\title{
In vivo Antinociceptive and Anti-inflammatory Activities of Dried and Fermented Processed Virgin Coconut Oil
}

\author{
Z.A. Zakaria ${ }^{a}{ }^{b} \quad$ M.N. Somchit ${ }^{a} \quad$ A.M. Mat Jais ${ }^{a} \quad$ L.K. Teh ${ }^{b} \quad$ M.Z. Salleh ${ }^{b}$ \\ K. Long ${ }^{c}$ \\ a Department of Biomedical Science, Faculty of Medicine and Health Sciences, Universiti Putra Malaysia, \\ Serdang, ${ }^{b}$ Pharmacogenomics Center, Faculty of Pharmacy, Universiti Teknologi MARA, Puncak Alam, and \\ 'Biotechnology Research Centre, Malaysian Agriculture Research Institute, Kuala Lumpur, Malaysia
}

\section{Key Words}

Virgin coconut oil • Antinociceptive activity •

Anti-inflammatory activity

\begin{abstract}
Objective: The present study was carried out to investigate the antinociceptive and anti-inflammatory activities of virgin coconut oil (VCO) produced by the Malaysian Agriculture Research and Development Institute (MARDI) using various in vivo models. Materials and Methods: Two types of VCOs, produced via standard drying (VCOA) and fermentation (VCOB) processes were used in this study. Both VCOA and VCOB were serially diluted using $1 \%$ Tween 80 to concentrations (v/v) of 10, 50 and 100\%. Antinociceptive and antiinflammatory activities of both VCOs were examined using various in vivo model systems. The antinociceptive activity of the VCOs were compared to those of 1\% Tween 80 (used as a negative control), morphine (5 mg/ $\mathrm{kg}$ ) and/or acetylsalicylic acid (100 mg/kg). Results: Both VCOA and VCOB exhibited significant $(p<0.05)$ dose-dependent antinociceptive activity in the acetic acid-induced writhing test. Both VCOs also exerted significant $(p<0.05)$ antinociceptive activity in both phases of the formalin and hot-plate tests. Interestingly, the VCOs exhibited anti-inflammatory activity in an acute (carrageenan-induced paw edema test), but not in a chronic (cotton-pellet-induced granuloma test) model of inflamma-
\end{abstract}

tion. Conclusion: The MARDI-produced VCOs possessed antinociceptive and anti-inflammatory activities. Further studies are needed to confirm these observations.

Copyright $\odot 2011$ S. Karger AG, Basel

\section{Introduction}

In addition to providing food, drink, and a key constituent of numerous cosmetic products, all of which have imparted wealth to various people throughout the world, Cocos nucifera L., of the family Palmae, more familiarly known as coconut, is also used in Malay traditional medicine to treat ailments such as fever, headaches, stomach upset and diarrhea. We have previously reported on the anti-inflammatory, antipyretic and wound healing properties of the fresh juice and kernel extracts of C. nucife$r a[1]$.

Recently, the focus of research on C. nucifera has shifted towards virgin coconut oil (VCO) and its benefits in the pharmaceutical, neutraceutical, cosmetic and industrial fields. The processes used to obtain VCO, which involve the use of controlled temperature, are believed to result in a preparation that has more beneficial effects than copra oil due to the greater retention of its active components, such as squalene, tocopherols and sterols [2]. Copra oil, on the other hand, is prepared by subject-

Dr. Zainul Amiruddin Zakaria

Department of Biomedical Science, Faculty of Medicine and Health Sciences Universiti Putra Malaysia

43400 UPM Serdang, Selangor (Malaysia)

Tel. +60 38947 2654, Fax +60 38943 6178, E-Mail dr_zaz@yahoo.com
(C) 2011 S. Karger AG, Basel

$1011-7571 / 11 / 0203-0231 \$ 38.00 / 0$

on $\mathrm{com} / \mathrm{mpp}$ 
ing the copra's crude oil to high temperatures up to $200^{\circ} \mathrm{C}$ to deodorize the oil. The advantage of using VCO over copra oil has been further supported by studies wherein VCO has been reported to have reduced total cholesterol, triacylglycerols, phospholipids, low-density lipoprotein (LDL) and very-low-density lipoprotein (VLDL) cholesterol and to have increased high-density lipoprotein levels in serum and tissues compared to copra oil $[3,4]$. Moreover, it has been reported that VCO is capable of increasing the activity of antioxidant enzymes and of reducing lipid peroxide levels and also has greater antithrombotic activity than copra oil $[4,5]$.

Despite such claims for C. nucifera, there have been no studies on the pharmacological properties of VCOs produced by the Malaysian Agricultural Research and Development Institute (MARDI) using animal models. Therefore, the aim of the present study was to investigate the potential role of MARDI-produced VCO as an antinociceptive and anti-inflammatory agent using various established in vivo animal models.

\section{Materials and Methods}

\section{Samples}

MARDI-produced VCOs, labeled as VCOA and VCOB, were donated by Dr. Kamariah Long from the Malaysian Agricultural Research and Development Institute (MARDI), Serdang, Malaysia. Briefly, VCOA was prepared using a standard drying method while VCOB was prepared via a fermentation process.

\section{Preparation of VCO Concentrations}

The freshly prepared VCOs, thought to have a concentration strength of $100 \%$, were serially diluted in $1 \%$ Tween $80(\mathrm{v} / \mathrm{v})$ to $10 \%$ and $50 \%$ concentration levels. The $10 \%, 50 \%$ and $100 \%$ concentrations of each VCO were then used in the present study.

Preparation of Drugs

Acetylsalicylic acid (ASA) (100 mg/kg; Bayer, Singapore) and morphine ( $5 \mathrm{mg} / \mathrm{kg}$; Sigma, Taufkirchen, Germany), used for the purpose of comparison, were prepared by dissolving them in distilled water $\left(\mathrm{dH}_{2} \mathrm{O}\right)$.

\section{Experimental Animals}

Male Balb-C mice (25-30 g; 5-7 weeks old) and Sprague-Dawley rats (180-200 g; 8-10 weeks old), obtained from the Animal Source Unit, Faculty of Veterinary Medicine, Universiti Putra Malaysia (UPM), Serdang, Selangor, Malaysia, were used in this study. All animals were housed at room temperature $\left(27 \pm 2{ }^{\circ} \mathrm{C} ; 70-80 \%\right.$ humidity; $12 \mathrm{~h}$ light/darkness cycle) in the Animal Holding Unit, Faculty of Medical and Health Sciences, UPM for at least $48 \mathrm{~h}$ before use. Food and water were supplied ad libitum up to the beginning of the experiments. At all times, the rats were cared for in accordance with the current UPM principles and guidelines for the care of laboratory animals (reference code: UPM/FPSK/PADS/
BRUUH/00221) and the UPM ethical guidelines for investigations of experimental pain in conscious animals as adopted from Zimmermann [6]. Test solutions were administered orally via gastric gavage. All experimental animals were killed by cervical dislocation according to the UPM ethical guidelines described earlier.

\section{Antinociceptive Assays}

Acetic Acid-Induced Abdominal Writhing Test. The abdominal writhing test was carried out according to the procedure described previously by Zakaria et al. [7]. Briefly, selected mice were divided into eight groups $(n=7)$ and pre-treated orally (p.o.) with $1 \%$ Tween 80 (control group), $100 \mathrm{mg} / \mathrm{kg}$ acetylsalicylic acid (ASA), VCOA or VCOB (10, 50 or 100\%), respectively. Thirty minutes after the pre-treatment, each group was injected intraperitoneally (i.p.) with $0.6 \%$ acetic acid $(10 \mathrm{ml} / \mathrm{kg})$ and the mice were placed in transparent Perspex observation boxes. After a 5-min lag period following the administration of acetic acid, the presence of contractions of abdominal muscle together with stretching of hind limbs (writhing effect) were cumulatively counted for $25 \mathrm{~min}$. The number of writhing and stretching movements was used to express the percentage of analgesia using the following ratio:

$\%$ analgesia $=\frac{\text { Mean of control group }- \text { Mean of test group }}{\text { Mean of control group }} \times 100$

Hot Plate Test. The hot plate test was performed using the method described previously by Zakaria et al. [8]. Before beginning the experiment, a group of untreated mice was subjected to a selection process by placing each on the Ugo Basile 7280 hot plate set at $53 \pm 0.5^{\circ} \mathrm{C}$. Only those mice with response latency times between 5-7 s were selected for this study. Briefly, selected mice were divided into eight groups $(\mathrm{n}=7)$ and pre-treated orally (p.o.) with $1 \%$ Tween $80,5 \mathrm{mg} / \mathrm{kg}$ morphine or, VCOA or VCOB $(10,50$ or $100 \%)$, respectively. Thirty minutes after the pre-treatment, animals were tested. The latency time of response to discomfort, observed when the animal started licking its fore- or hind-paws or jumped when placed on the hot plate, was recorded immediately ( $0 \mathrm{~min}$ ) and at 30, 60, 120, 180, 240 and $300 \mathrm{~min}$ after the administration of each test solution. A cut-off time of $20 \mathrm{~s}$ was adopted to avoid excessive tissue damage to the animals. A prolongation of latency time relative to untreated controls was taken as an indicator of antinociceptive activity.

Formalin-Induced Paw Licking Test. The method described by Zakaria et al. [9] was adopted in the present study. Rats were placed in the observation chamber to familiarize them with their surroundings for an initial $20 \mathrm{~min}$ of accommodation. Selected rats $(\mathrm{n}=7)$ were pre-treated (p.o.) with $1 \%$ Tween $80,100 \mathrm{mg} / \mathrm{kg}$ ASA, $5 \mathrm{mg} / \mathrm{kg}$ morphine or, VCOA or $\mathrm{VCOB}(10,50$ or $100 \%)$ $30 \mathrm{~min}$ prior to the intraplantar (i.pl.) injection of $50 \mu \mathrm{l}$ of $2.5 \%$ formalin into the right hind paw. The length of time following the injection of formalin the animal spent licking and biting the injected paw, which indicated pain, was recorded. Responses were recorded between 0 and $5 \mathrm{~min}$, and 15 and $30 \mathrm{~min}$ after formalin administration - these represent the early and late phases of this test, respectively. The percentage of analgesia was calculated using the formula below:

$\%$ analgesia $=\frac{\text { Mean of control group }- \text { Mean of test group }}{\text { Mean of control group }} \times 100$ 
Anti-Inflammatory Assays

Carrageenan-Induced Paw Edema Test. The procedure described by Zakaria et al. [10] was used to determine the anti-inflammatory activity of VCOs in this model of acute inflammation. Rats were divided into 5 groups $(\mathrm{n}=7)$ and received (p.o.) $1 \%$ Tween $80,100 \mathrm{mg} / \mathrm{kg}$ ASA or, VCOA or VCOB $(10,50$ or $100 \%)$ followed $30 \mathrm{~min}$ later by the administration (i.pl.) of $0.1 \mathrm{ml}$ of a $1 \%$ carrageenan suspension into the right hind paw. Paw volume was measured before $\left(\mathrm{V}_{0}\right)$ and at 1, 2, 3, 4, 5 and $6 \mathrm{~h}\left(\mathrm{~V}_{\mathrm{T}}\right)$ following carrageenan injection using a plethysmometer (Model 7140, Ugo Basile, Italy). The degree of inflammation was quantified by measuring the volume displaced by the paw between the final volume $\left(V_{T}\right)$ and the initial volume $\left(V_{0}\right)$. The percentage of anti-inflammation was calculated using the formula:

$\%$ anti-inflammation $=[(V \downarrow T-V \downarrow 0) \downarrow($ control $)-$

$(V \downarrow T-V \downarrow 0) \downarrow$ (treated) $] /[(V \downarrow T-V \downarrow 0) \downarrow($ control $)] \times 100$

where $\mathrm{T}=$ time interval.

Cotton Pellet-Induced Granuloma Test. The procedure described by Sulaiman et al. [11] was used to study the anti-inflammatory activity of VCOs in this model of chronic inflammation. Cotton pellets, weighing approximately $50 \mathrm{mg}$ each, were autoclaved for $2 \mathrm{~h}$. The autoclaved cotton pellets were implanted at intrascapular distance, or dorsum region, aseptically under the skin on the shaved backs of rats anesthetized with $1 \mathrm{ml} / \mathrm{kg}$ avertin (i.p.). The anaesthetized rats were divided into 5 groups $(n=7)$ and received (p.o.) 1\% Tween $80,100 \mathrm{mg} / \mathrm{kg}$ ASA or, VCOA or VCOB (10, 50 or $100 \%)$. All test solutions were given once a day for a period of 7 days and the rats were killed on the 8 th day by cervical dislocation according to the UPM ethical guidelines as described earlier. The wet cotton pellets, surrounded by granuloma tissue were dissected out, weighed, and then dried at $60^{\circ} \mathrm{C}$ and weighed again. The percentage of anti-inflammatory activity of VCOs, indicated by its ability to reduce the accumulation of granuloma tissue, was calculated using the following equation:

$$
\% \text { anti-inflammation }=\frac{T_{C}-T_{T}}{T_{C}} \times 100
$$

where $\mathrm{T}_{\mathrm{C}}=$ weight of granuloma tissue of the control group, and $\mathrm{T}_{\mathrm{T}}=$ weight of granuloma tissue of the treated group.

\section{Statistical Analysis}

The results are expressed as mean \pm SEM. Data for the abdominal constriction, formalin and cotton pellet-induced granuloma tests were analyzed using one-way analysis of variance (ANOVA) followed by Dunnet's multiple comparison test among groups. Data for the hot plate and carrageenan-induced paw edema tests were analyzed using two-way ANOVA followed by Tukey's posthoc test among groups. $\mathrm{p}<0.05$ was taken as the limit of significance in all tests. All statistical analyses were carried out using the SPSS 11.0.0 for Windows (SPSS Inc., Chicago, Ill., USA) program.

\section{Results}

The antinociceptive profiles of VCOA and VCOB assessed using the acetic acid-induced abdominal constriction test in mice are given in table 1. Both VCOs exhibited concentration-dependent antinociception with 50\%
Table 1. Antinociceptive activity of MARDI-produced VCOs assessed by the acetic acid-induced writhing test in mice

\begin{tabular}{lcll}
\hline $\begin{array}{l}\text { Treatment } \\
\text { groups }(\mathrm{n}=7)\end{array}$ & $\begin{array}{l}\text { Concen- } \\
\text { tration } \\
\text { strength, } \%\end{array}$ & $\begin{array}{l}\text { No. of writhing } \\
\text { responses } \pm \text { SEM }\end{array}$ & $\begin{array}{l}\text { Percentage } \\
\text { of } \\
\text { analgesia }\end{array}$ \\
\hline 1\% Tween 80 & - & $47.6 \pm 2.4$ & - \\
$100 \mathrm{mg} / \mathrm{kg} \mathrm{ASA}$ & - & $12.2 \pm 1.1^{*}$ & 74.4 \\
VCOA & 10 & $36.4 \pm 1.7^{*}$ & 23.5 \\
& 50 & $30.1 \pm 2.2^{*, \#}$ & 36.8 \\
VCOB & 100 & $18.3 \pm 1.7^{*}$ & 61.6 \\
& 10 & $31.3 \pm 1.6^{*}$ & 34.2 \\
& 50 & $22.5 \pm 0.8^{*}$ & 52.7 \\
& 100 & $20.9 \pm 2.1^{*}$ & 56.1 \\
\hline
\end{tabular}

ASA = Acetylsalicylic acid; $\mathrm{VCOA}=$ virgin coconut oil A; $\mathrm{VCOB}=$ virgin coconut oil $\mathrm{B}$. The writhing response was expressed as mean \pm SEM.

${ }^{*} \mathrm{p} \leq 0.05$ compared with the $1 \%$ Tween 80 -treated group.

${ }^{*} \mathrm{p} \leq 0.05$ compared with the $50 \%$ VCOB-treated group.

VCOB showing an antinociceptive activity that was significantly $(\mathrm{p}<0.05)$ greater than that of $50 \%$ VCOA. Overall, the maximal antinociceptive activities elicited by both VCOs were significantly $(\mathrm{p}<0.05)$ lower than that obtained with $100 \mathrm{mg} / \mathrm{kg}$ ASA.

The antinociceptive profiles of VCOA and VCOB assessed using the hot plate test in mice are given in table 2 . Both VCOs exhibited significant $(\mathrm{p}<0.05)$ antinociceptive activity with a maximal effect exhibited by the intermediate concentration. Overall, based on the results obtained, all concentrations of $\mathrm{VCOB}$ exhibited greater antinociceptive activity when compared to the respective concentration of VCOA. In addition, only 10 and 50\% VCOA exhibited a loss of activity at the end of the study (at interval $6 \mathrm{~h}$ ). Overall, $5 \mathrm{mg} / \mathrm{kg}$ morphine exerted an antinociceptive activity that was greater than that of either of the VCOs at all concentrations investigated.

The antinociceptive profiles of VCOA and VCOB assessed using the formalin test in rats are given in table 3. Comparison with the control group (1\% Tween 80 ) showed that both VCOs reduced the latency of discomfort induced by formalin in both phases, indicating their antinociceptive activity. Interestingly, only $10 \%$ VCOB exhibited significant $(\mathrm{p}<0.05)$ antinociceptive activity in the early phase compared to $10 \%$ VCOA ( $p \geq 0.05$ ). Overall, $5 \mathrm{mg}$ / $\mathrm{kg}$ morphine exhibited activity that was greater than that of either of the VCOs in both phases of the formalin test, while $100 \mathrm{mg} / \mathrm{kg}$ ASA produced antinociception that was greater than that of either VCO in the late phase. 
Table 2. Antinociceptive activity of MARDI-produced VCOs assessed by the $50^{\circ} \mathrm{C}$ hot plate test in mice

\begin{tabular}{|c|c|c|c|c|c|c|c|c|}
\hline \multirow{2}{*}{$\begin{array}{l}\text { Treatment groups } \\
(\mathrm{n}=7)\end{array}$} & \multirow{2}{*}{$\begin{array}{l}\text { Concentration } \\
\text { strength, } \%\end{array}$} & \multicolumn{7}{|c|}{ Latency of discomfort (s) } \\
\hline & & $0 \mathrm{~min}$ & $30 \mathrm{~min}$ & $60 \mathrm{~min}$ & $120 \mathrm{~min}$ & $180 \mathrm{~min}$ & $240 \mathrm{~min}$ & $360 \mathrm{~min}$ \\
\hline $5 \mathrm{mg} / \mathrm{kg}$ morphine & - & $7.8 \pm 0.6$ & $15.9 \pm 0.8^{*}$ & $17.8 \pm 0.6^{*}$ & $14.2 \pm 1.1^{*}$ & $12.6 \pm 0.9^{*}$ & $13.8 \pm 1.1^{*}$ & $10.9 \pm 0.8^{*}$ \\
\hline \multirow[t]{2}{*}{ VCOA } & 10 & $7.4 \pm 0.5$ & $8.1 \pm 0.6$ & $9.2 \pm 0.9$ & $8.7 \pm 0.4$ & $9.7 \pm 0.7$ & $9.2 \pm 0.3$ & $8.7 \pm 0.7$ \\
\hline & 50 & $7.7 \pm 0.3$ & $7.8 \pm 0.7$ & $12.5 \pm 0.9^{*}$ & $11.0 \pm 0.4^{*}$ & $11.1 \pm 0.8^{*}$ & $11.0 \pm 0.2^{*}$ & $9.3 \pm 0.4$ \\
\hline \multirow{2}{*}{ VCOB } & 50 & $7.3 \pm 0.6$ & $10.5 \pm 0.8^{*, \S}$ & $12.7 \pm 1.0^{*}$ & $10.7 \pm 0.7^{*}$ & $10.2 \pm 0.4^{*}$ & $10.2 \pm 0.2^{*}$ & $10.9 \pm 0.5^{*}$ \\
\hline & 100 & $7.4 \pm 0.1$ & $10.2 \pm 0.5^{*}$ & $12.7 \pm 0.6^{*, \$}$ & $14.8 \pm 0.7^{*}, \$$ & $10.8 \pm 0.9^{*}$ & $11.8 \pm 0.4^{*, \$}$ & $12.9 \pm 0.8^{*}$ \\
\hline
\end{tabular}

$\mathrm{VCOA}=$ Virgin coconut oil A; VCOB = virgin coconut oil B. The latency for licking of the hind paws, shaking or jumping off from the surface was expressed as mean \pm SEM.

${ }^{*} \mathrm{p} \leq 0.05$ compared with the $1 \%$ Tween 80 -treated group. ${ }^{*} \mathrm{p} \leq 0.05$ compared with the $10 \%$ VCOA-treated group at the respective time interval. ${ }^{\S} \mathrm{p} \leq 0.05$ compared with the $50 \%$ VCOA-treated group at the respective time interval. ${ }^{\$} \mathrm{p} \leq 0.05$ compared with the $100 \%$ VCOA-treated group at the respective time interval.

Table 3. Antinociceptive activity of MARDI-produced VCOs assessed by the formalin test in mice

\begin{tabular}{|c|c|c|c|c|c|}
\hline \multirow[t]{2}{*}{ Treatments } & \multirow{2}{*}{$\begin{array}{l}\text { Concen- } \\
\text { tration } \\
\text { strength, } \\
\%\end{array}$} & \multicolumn{2}{|c|}{$\begin{array}{l}\text { Mean of licking time }(\mathrm{s}) \pm \\
\text { SEM }\end{array}$} & \multicolumn{2}{|c|}{$\begin{array}{l}\text { Percentage of } \\
\text { analgesia }\end{array}$} \\
\hline & & $\begin{array}{l}\text { early phase } \\
0-5 \text { th min }\end{array}$ & $\begin{array}{l}\text { late phase } \\
\text { 15-30th min }\end{array}$ & $\begin{array}{l}\text { early } \\
\text { phase }\end{array}$ & $\begin{array}{l}\text { late } \\
\text { phase }\end{array}$ \\
\hline 1\% Tween 80 & - & $53.3 \pm 3.3$ & $82.3 \pm 4.8$ & - & - \\
\hline $100 \mathrm{mg} / \mathrm{kg}$ ASA & - & $49.7 \pm 2.7$ & $16.7 \pm 2.1^{*}$ & 6.9 & 79.8 \\
\hline $5 \mathrm{mg} / \mathrm{kg}$ morphine & - & $4.2 \pm 0.9^{*}$ & $2.7 \pm 0.7^{*}$ & 92.1 & 96.7 \\
\hline \multirow[t]{3}{*}{ VCOA } & 10 & $50.0 \pm 2.0$ & $30.5 \pm 2.9^{*}$ & 6.0 & 63.0 \\
\hline & 50 & $20.3 \pm 1.5^{*}$ & $36.3 \pm 1.8^{*}$ & 61.9 & 55.9 \\
\hline & 100 & $39.2 \pm 4.2^{*}$ & $44.0 \pm 5.2^{*}$ & 26.4 & 46.6 \\
\hline \multirow[t]{3}{*}{ VCOB } & 10 & $38.3 \pm 3.0^{*}$ & $40.0 \pm 4.0^{*}$ & 28.3 & 51.4 \\
\hline & 50 & $39.0 \pm 3.2^{*}$ & $45.0 \pm 3.3^{*}$ & 26.9 & 45.3 \\
\hline & 100 & $32.5 \pm 2.2^{*}$ & $20.0 \pm 1.4^{*}$ & 39.1 & 75.7 \\
\hline
\end{tabular}

${ }^{*} \mathrm{p} \leq 0.05$ compared with the $1 \%$ Tween 80 -treated group.

The anti-inflammatory profiles of VCOA and VCOB assessed using the carrageenan-induced paw edema test in rats are given in table 4 . Both VCOs exhibited significant $(\mathrm{p}<0.05)$ anti-inflammatory activity with VCOB showing a greater effect than VCOA. This is indicated by the ability of VCOB at all concentrations tested to exert an anti-inflammatory effect compared to only the highest concentration of VCOA (100\%). In addition, the onset of action of 10 and $50 \% \mathrm{VCOB}$ was $3 \mathrm{~h}$ while the onset of action for $100 \%$ VCOB was $0.5 \mathrm{~h}$ following VCOB administration. For 100\% VCOA, the onset of action was $1 \mathrm{~h}$ after VCOA administration. A comparison to $100 \mathrm{mg} / \mathrm{kg}$ ASA indicates that $100 \%$ VCOB possessed greater activity than ASA throughout the experiment.

Pretreatment of rats with VCOA or VCOB at all concentrations failed to attenuate chronic inflammation as seen with cotton pellet-induced granuloma test (data not shown).

\section{Discussion}

The present study has indicated the potential of MARDI-produced VCOs as antinociceptive and antiinflammatory agents, and validated the traditional use of C. nucifera in the treatment of pain- and inflammationrelated ailments such as fever and headache. The VCOs were found to exhibit antinociceptive activity when assessed using the abdominal constriction and hot plate tests, thus indicating their effectiveness in blocking peripherally and centrally mediated nociception induced by chemical and thermal stimuli $[12,13]$. Furthermore, because both VCOs inhibited the hot plate test, this suggested their ability to block a noninflammatory, acute nociceptive input. The peripheral and central effects of VCOs on nociceptive processes were further confirmed by the effectiveness of VCOs in attenuating the formalin test [14]. The antinociceptive effects of the VCOs seen in both phases of the formalin test indicated their ability to directly block the formalin-induced nociceptor stimulation seen with the early phase and to block the subsequent 
Table 4. Anti-inflammatory profile of MARDI-produced VCOs on acute inflammation assessed by carrageenan-induced paw edema test in rats

\begin{tabular}{|c|c|c|c|c|c|c|c|c|c|}
\hline $\begin{array}{l}\text { Treatment } \\
\text { group }(n=7)\end{array}$ & $\begin{array}{l}\text { Concen- } \\
\text { tration } \\
\text { strength, \% }\end{array}$ & \multicolumn{8}{|c|}{ Thickness of edematous paw (mm) } \\
\hline $100 \mathrm{mg} / \mathrm{kg}$ ASA & - & $1.47 \pm 0.07$ & $1.63 \pm 0.09$ & $1.53 \pm 0.07$ & $1.55 \pm 0.06^{*}$ & $1.53 \pm 0.02^{*}$ & $1.54 \pm 0.07^{*}$ & $1.50 \pm 0.05^{*}$ & $1.49 \pm 0.10^{*}$ \\
\hline \multirow[t]{2}{*}{ VCOA } & 10 & $1.46 \pm 0.06$ & $1.70 \pm 0.04$ & $1.72 \pm 0.08$ & $1.80 \pm 0.06$ & $1.89 \pm 0.04$ & $1.99 \pm 0.03$ & $1.89 \pm 0.09$ & $1.92 \pm 0.04$ \\
\hline & 50 & $1.48 \pm 0.05$ & $1.62 \pm 0.06$ & $1.66 \pm 0.10$ & $1.68 \pm 0.04$ & $1.80 \pm 0.07$ & $1.83 \pm 0.08$ & $1.86 \pm 0.02$ & $1.81 \pm 0.07$ \\
\hline \multirow{2}{*}{$\mathrm{VCOB}$} & 50 & $1.47 \pm 0.03$ & $1.58 \pm 0.04^{*}$ & $1.59 \pm 0.06^{*}$ & $1.64 \pm 0.05^{*}$ & $1.61 \pm 0.07^{*}$ & $1.60 \pm 0.06^{*}$ & $1.53 \pm 0.04^{*}$ & $1.52 \pm 0.16^{*}$ \\
\hline & 100 & $1.45 \pm 0.08$ & $1.61 \pm 0.06$ & $1.51 \pm 0.04^{*}$ & $1.52 \pm 0.03^{*}$ & $1.49 \pm 0.09^{*}$ & $1.48 \pm 0.60^{*}$ & $1.47 \pm 0.05^{*}$ & $1.47 \pm 0.04^{*}$ \\
\hline
\end{tabular}

ASA = Acetylsalicylic acid; $\mathrm{VCOA}=$ virgin coconut oil A; VCOB = virgin coconut oil $\mathrm{B}$. The thickness of edematous hind paw was expressed as mean \pm SEM.

* $\mathrm{p} \leq 0.05$ compared with the $1 \%$ Tween 80 -treated group in the same period.

release of inflammatory mediators. The anti-inflammatory activity of VCOs was demonstrated with the carrageenan-induced rat paw edema test, but not the cottonpellet granuloma test. The former, usually used as a basic test to study the anti-inflammatory activity of compounds/bioactive agents, is considered to be an acute model of inflammation $[9,15]$. The ability of both VCOs to reduce paw edema therefore indicates their ability to reduce acute inflammation. However, both VCOs were inactive in the chronic model of inflammation.

To speculate on the possible mechanisms involved in the ability of both VCOs to attenuate acute, but not chronic, inflammation, it is worth mentioning the different types of mediators that are found in both phases of inflammation. During acute inflammation, signaling molecules and chemoattractants (e.g. bradykinin, histamine, serotonin, nitric oxide, eicosanoids, etc.) are released at the site of an infection or injury by various types of cells (such as mast cells, platelets, nerve endings, endothelial cells, and other resident cells) [16]. Chronic inflammation, on the other hand, is mediated primarily by macrophages that are involved in perpetuating the proinflammatory response via the release of various chemical mediators (i.e. IL-1, IL-6 and tumor necrosis factor (TNF)- $\alpha$ ). Based on the difference between the types of inflammatory mediators release during acute and chronic inflammations, and the ability of both VCOs to inhibit only the former, it is speculated that VCOA and VCOB act against signaling molecules and chemoattractants that are short-lived and released at the site of an infection or injury rather than those released during chronic inflammation. Another mechanism might involve the attenuation of ROS activity. This might involve antioxidant activity of both VCOs associated with the presence of polyphenolic compounds [unpubl. data]. Other than that, it can also be speculated that the VCOs possess a short duration of action and are rapidly metabolized and eliminated from the body. This could explain their failure to affect the chronic inflammatory processes seen with cotton pellet-induced granuloma test. However, further studies are required before a final conclusion could be reached on this matter.

VCO has been reported to contain polyphenols $[2,3]$ and polyphenols have been reported to possess various biological actions, including antinociceptive and antiinflammatory activities $[17,18]$ and to affect signal transduction, activation of pro-inflammatory transcription factors and gene expression [19]. In a recently submitted study, we have demonstrated the antiulcerogenic and antioxidant activities of VCOA and VCOB [unpubl. data] and have shown that these activities are due, at least in part, to their polyphenol content. The total antioxidant activity and total phenolic content of VCOA and VCOB were 75.7 and $82.4 \%$, and 12.8 and $23.5 \mathrm{mg} \mathrm{GAE} / 100 \mathrm{~g}$ oil, respectively. Thus, the presence of polyphenolic compounds may contribute to the observed antinociceptive and anti-inflammatory activities of VCOA and VCOB.

In another study, the antihypercholesterolemia activity and fatty acid composition of VCOA and VCOB was explored [20]. The main fatty acids found in VCOA in- 
cluded lauric (50\%), myristic (18\%), caprylsic (9\%), palmitic (7\%), capric (7\%), oleic (5\%) and stearic (3\%) acids, while those of VCOB include lauric (47\%), myristic (19\%), palmitic (9\%), caprylic (8\%), oleic $(6 \%)$, capric $(6 \%)$ and stearic (3\%) acids. Fatty acids such as oleic and stearic acids have been shown to attenuate the activity of polymorphonuclear leukocytes leading to the suppression of inflammatory processes [21]. It is suggested that the proportion of fatty acids integrated into membrane phospholipids affect membrane fluidity, which in turn can influence cell function. This is due to the fact that membrane fluidity is affected by the chain length and saturation of phospholipid fatty acids [21]. The presence of unsaturated (i.e. palmitic and stearic acids) and monounsaturated (i.e. oleic acid) fatty acids in both VCOs undoubtedly influences membrane fluidity and will affect many cell functions, including PMN activation. It has been claimed that compounds with anti-inflammatory activity might also exhibit antinociceptive activity [9]. It is therefore plausible to suggest that the pharmacological activities observed in the present study could be associated with the presence of polyphenols and fatty acids in both VCOs.

\section{Conclusion}

The MARDI-produced VCOs possess antinociceptive and anti-inflammatory activities with the former mediated via peripheral and central nociceptive mechanisms while the later being effective only against the acute model of inflammation, and thus requiring further in-depth investigation.

\section{Acknowledgements}

This study was supported by the Ministry of Science, Technology and Innovation (MOSTI), Malaysia TechnoFund (Project No. TF 106B139). The authors would like to thank Universiti Putra Malaysia and Universiti Teknologi MARA for the facilities.

\section{References}

1 Zakaria ZA, Reezal I, Mat Jais AM, Marmin AHI, Sidek H, Husin SH, Rahim MHA, Sabtu L, Somchit MN, Sulaiman MR: The antiinflammatory, antipyretic and wound healing activities of Cocos nucifera (MATAG Types) fresh juice and kernel extracts in experimental animals. J Pharmacol Toxicol 2006;1:516-526.

2 Marina AM, Che Man YB, Nazimah AH: Chemical properties of virgin coconut oil. J Am Oil Chem Soc 2009;86:301-307.

3 Nevin KG, Rajamohan T: Beneficial effects of virgin coconut oil on lipid parameters and in vitro LDL oxidation. Clin Biochem 2004; 37:830-835.

4 Nevin KG, Rajamohan T: Influence of virgin coconut oil on blood coagulation factors, lipid levels and LDL oxidation in cholesterol fed Sprague-Dawley rats. Eur J Clin Nutr Metab 2008;3:1-8

5 Nevin KG, Rajamohan T: Virgin coconut oil supplemented diet increases the antioxidant status in rats. Food Chem 2006;99:260-266.

6 Zimmermann M: Ethical guidelines for investigations of experimental pain in conscious animals. Pain 1983;16:109-110.

7 Zakaria ZA, Raden Mohd Nor RNS, Hanan Kumar G, Abdul Ghani ZDF, Sulaiman MR, Rathna Devi G, Mat Jais AM, Somchit MN, Fatimah CA: Antinociceptive, anti-inflammatory and anti-pyretic properties of Melastoma malabathricum leaves aqueous extract in experimental animals. Can J Physiol Pharmacol 2006;84:1291-1299.

8 Zakaria ZA, Hanan Kumar G, Zainal H, Mohd Pojan NH, Morsid NA, Aris A, Sulai- man MR: Antinociceptive, anti-inflammatory and antipyretic effects of Solanum nigrum chloroform extract in animal models. Yakugaku Zasshi 2006;126:1171-1178.

9 Zakaria ZA, Hanan Kumar G, Raden Mohd Nor RNS, Sulaiman MR, Fatimah CA, Mat Jais AM, Somchit MN, Ismail MS: Antinociceptive, anti-inflammatory and antipyretic properties of Corchorus capsularis leaves aqueous extract in experimental animal models. Pharm Biol 2009;47:104-110.

10 Zakaria ZA, Sulaiman MR, Hanan Kumar G, Abdul Ghani ZDF, Raden Mohd Nor RNS, Rathna Devi G, Mat Jais AM, Fatimah CA: Antinociceptive and anti-inflammatory properties of Corchorus capsularis leaves chloroform extract in experimental animal models. Yakugaku Zasshi 2007;127:359-365.

11 Sulaiman MR, Zakaria ZA, Chiong HS, Lai SK, Israf DA, Tg Azam Shah TM: Antinociceptive and anti-inflammatory effects of Stachytarpheta jamaicensis (L.) Vahl. (Verbenaceae) in experimental animal models. Med Princ Pract 2009;18:272-279.

12 Bentley GA, Newton SH, Starr J: Evidence for an action of morphine and the enkephalins on sensory nerve endings in the mouse peritoneum. Br J Pharmacol 1981;73:325-332.

13 Pini LA, Vitale G, Ottani A, Sandrini M: Naloxone-reversible antinociception by paracetamol in the rat. J Pharmacol Exp Ther 1997;280:934-940.

14 Zakaria ZA, Hanan Kumar G, Mat Jais AM, Sulaiman MR, Somchit MN: Antinociceptive, anti-inflammatory and antipyretic properties of Channa striatus fillet aqueous and lipid-based extracts in rats. Methods Find Exp Clin Pharmacol 2008;30:355-362.

15 Winter CA, Risley EA, Nuss GW: Carrageenan-induced edema in hind paw of the rat as an assay for anti-inflammatory drugs. Proc Soc Exp Biol Med 1962;111:544-547.

16 Kahn MA, Solomon LW: Acute Inflammation/Wound Healing and Repair II. http:// ocw.tufts.edu/data/51/551543.pdf. 2007.

17 Dos Santos MD, Almeida MC, Lopes NP, de Souza GEP: Evaluation of the anti-inflammatory, analgesic and antipyretic activities of the natural polyphenol chlorogenic acid. Biol Pharm Bull 2006;29:2236-2240.

18 Küpeli E, Pinar SF, Ihsan C, Yesilada E, Ezer $\mathrm{N}$ : Phenolic compounds of Sideritis ozturkii and their in vivo anti-inflammatory and antinociceptive activities. J Ethnopharmacol 2007;112:356-360

19 Natarajan K, Singh S, Burke TR, Grunberger D, Aggarwal BB: Caffeic acid phenethyl ester is a potent and specific inhibitor of activation of nuclear transcription factor NF-kappa B. Proc Natl Acad Sci USA 1996;93:9090-9095.

20 Zakaria ZA, Ahmad Z, Somchit MN, Arifah AK, Sulaiman MR, Teh LK, Salleh MZ, Long $\mathrm{K}$ : Antihypercholesterolemia property and fatty acid composition of MARDI-produced virgin coconut oils. Afr J Pharm Pharmacol 2010;4:636-644.

21 Zakaria ZA, Sulaiman MR, Goh YM, Mat Jais AM, Somchit MN: Determination of the amino acid and fatty acid compositions of the aqueous extract of Channa striatus (Haruan) that exhibits antinociceptive activity. Clin Exp Pharmacol Physiol 2007;34:198-204. 